\title{
SUPPLEMENTAL INFORMATION
}

PCB Bioavailability Control in Lumbriculus Variegatus through Different Modes of Activated Carbon Addition to Sediments

\section{Xueli Sun and Upal Ghosh}

Department of Civil and Environmental Engineering, University of Maryland Baltimore County, Baltimore, MD 21250

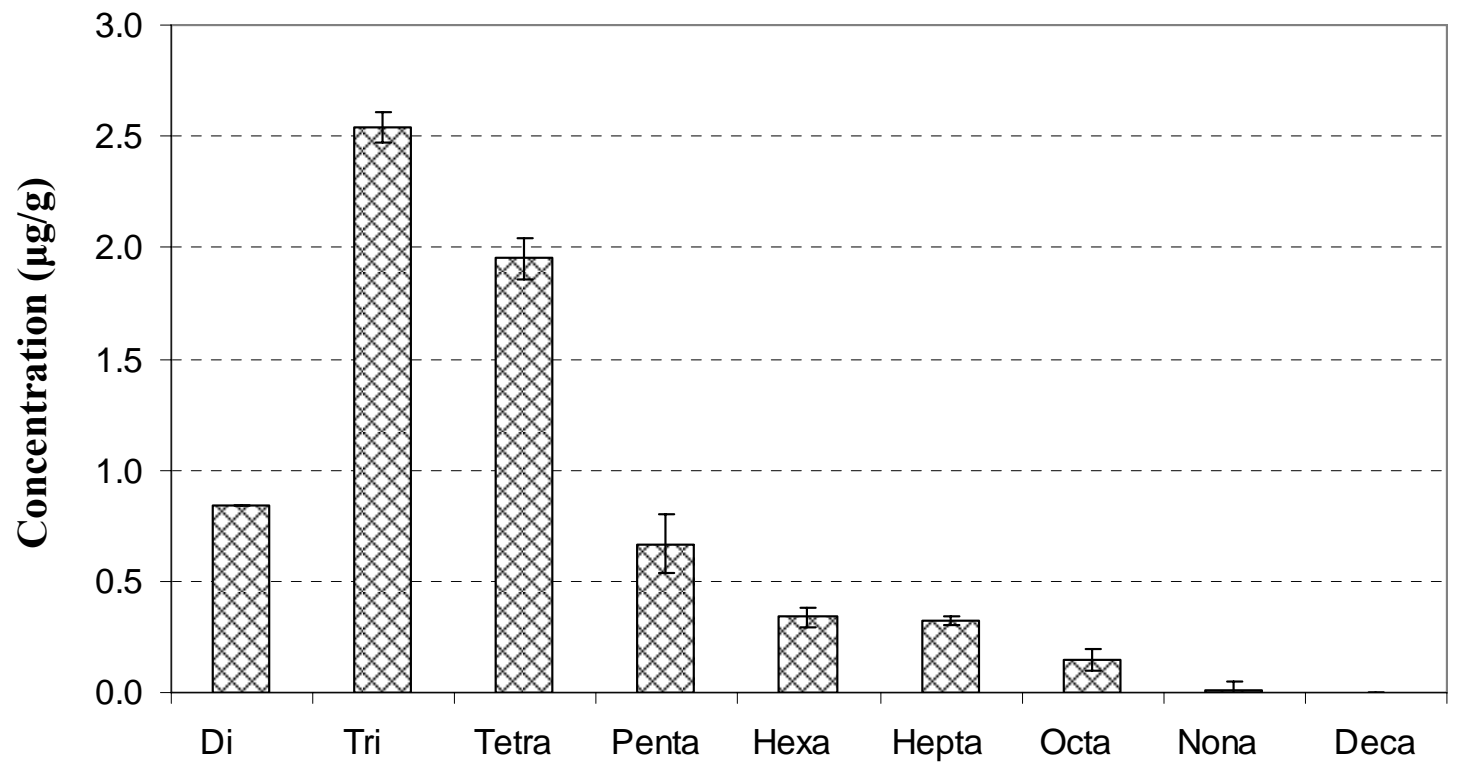

FIGURE S1. PCB homolog concentrations in study sediment. 


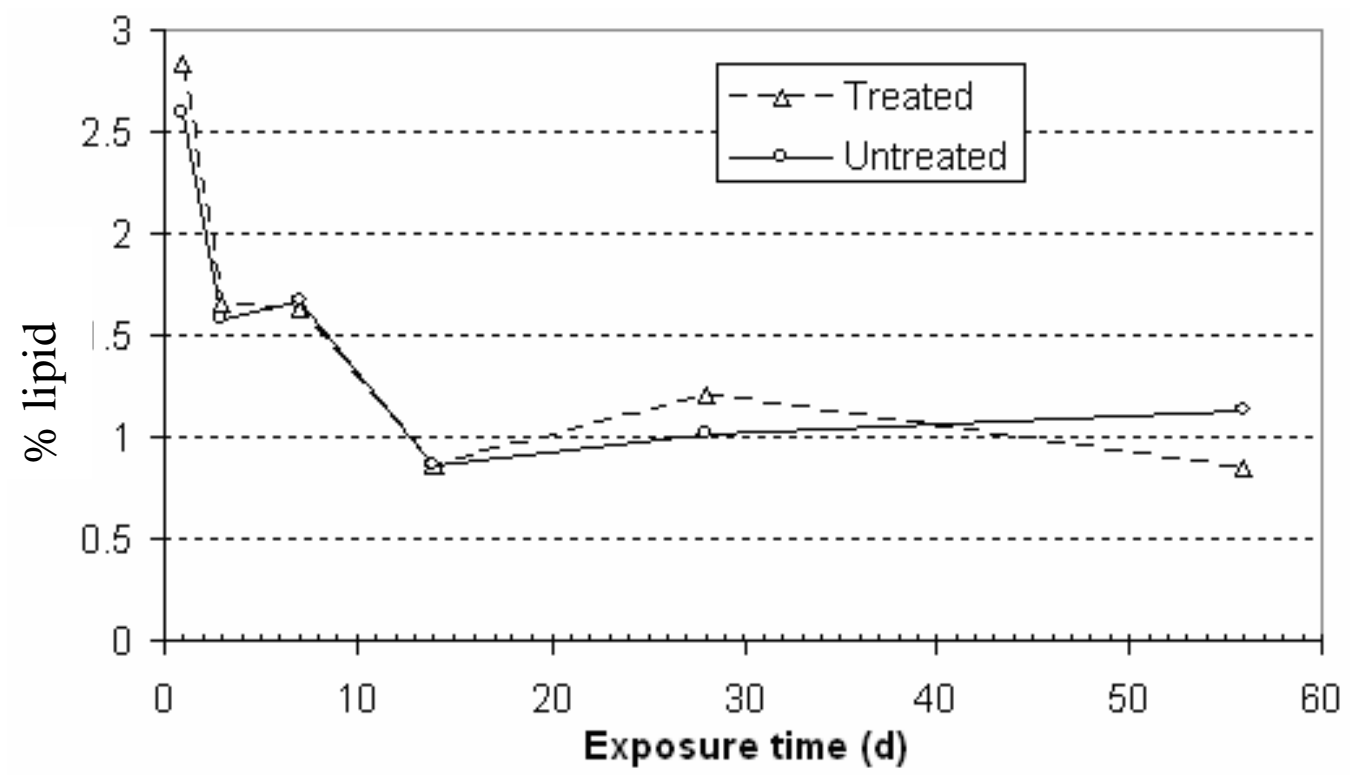

FIGURE S2. Change in organism lipid content during the 56 day biouptake kinetics experiment. 
<smiles>C#CC(C#C)(C#C)[Si](C#C)(C#C)C#C</smiles> 
TABLE S1. The rapid desorption fraction $(f)$ and desorption rate constants of PCB homolog groups for untreated sediment and sediment treated with GAC for one month.

\begin{tabular}{llllll}
\hline PCB & \multicolumn{2}{l}{ Untreated sediment } & \multicolumn{3}{l}{ Treated sediment } \\
homolog & $f$ & $k_{r}\left(\mathrm{~d}^{-1}\right)$ & $k_{s}\left(\mathrm{~d}^{-1}\right)$ & $f$ & $k_{s}\left(\mathrm{~d}^{-1}\right)$ \\
\hline Di & $0.83 \pm 0.02$ & $7.15 \pm 0.83$ & $0.082 \pm 0.006$ & $0.000 \pm 0.000$ & $0.001 \pm 0.000$ \\
Tri & $0.70 \pm 0.04$ & $4.55 \pm 0.02$ & $0.035 \pm 0.014$ & $0.037 \pm 0.006$ & $0.001 \pm 0.000$ \\
Tetra & $0.66 \pm 0.07$ & $2.28 \pm 0.84$ & $0.041 \pm 0.022$ & $0.098 \pm 0.006$ & $0.002 \pm 0.000$ \\
Penta & $0.68 \pm 0.07$ & $0.70 \pm 0.17$ & $0.022 \pm 0.011$ & $0.370 \pm 0.021$ & $0.002 \pm 0.001$ \\
Hexa & $0.68 \pm 0.09$ & $0.33 \pm 0.09$ & $0.020 \pm 0.009$ & $0.618 \pm 0.044$ & 0 \\
Hepta & $0.82 \pm 0.13$ & $0.11 \pm 0.02$ & $0.005 \pm 0.013$ & $0.805 \pm 0.022$ & $0.002 \pm 0.000$ \\
\hline
\end{tabular}

TABLE S2. the values of $\log \mathrm{Koc}(\mathrm{L} / \mathrm{kg})$ before and after GAC addition to the sediment and $\log K_{\mathrm{AC}}(\mathrm{L} / \mathrm{kg})$ in the presence and absence of sediment.

\begin{tabular}{lcccc}
\hline PCB homolog & \multicolumn{2}{c}{$\operatorname{LogK}_{\text {oc }}$} & \multicolumn{2}{c}{ LogK $_{\text {AC }}$} \\
& Before & After & Absence $^{\mathrm{a}}$ & Presence $^{\mathrm{b}}$ \\
\hline Di & 4.73 & 6.70 & 8.12 & 7.06 \\
Tri & 5.08 & 6.65 & 8.30 & 6.92 \\
Tetra & 5.56 & 6.41 & 9.17 & 6.60 \\
Penta & 5.93 & 6.22 & 9.50 & 6.15 \\
Hexa & 6.35 & 6.54 & 9.67 & 5.50 \\
Hepta & 6.56 & 6.71 & 9.79 & 5.14 \\
\hline
\end{tabular}

a: Taken or calculated from Jonker, et al. (2002).

b: Calculated based on the assumption that the reduction of rapid fraction of PCBs are transferred to the AC.

TABLE S3. Percent reductions in PCB aqueous equilibrium concentration after mixing sediments with coarse GAC for 1 and 6 months.

\begin{tabular}{lll}
\hline PCB homolog & One month contact & Six month contact \\
Di & $99.3 \pm 0.1$ & $99.9 \pm 0.1$ \\
Tri & $98.2 \pm 0.7$ & $99.6 \pm 0.0$ \\
Tetra & $90.4 \pm 3.7$ & $98.6 \pm 0.7$ \\
Penta & $64.3 \pm 4.5$ & $74.3 \pm 4.1$ \\
Hexa & $55.4 \pm 2.2$ & $54.5 \pm 3.4$ \\
Hepta & $51.9 \pm 12.9$ & $65.8 \pm 20.7$ \\
\hline
\end{tabular}




\section{Reference:}

Jonker, M. T. O.; Koelmans, A. A. Sorption of polycyclic aromatic hydrocarbons and polychlorinated biphenyls to soot and sootlike materials in the aqueous environment: mechanistic considerations. Environ. Sci. Technol. 2002, 36, 3725-3734. 